\title{
Cell-Type Specific Insertion of GluA2-Lacking AMPARs with Cocaine Exposure Leading to Sensitization, Cue-Induced Seeking, and Incubation of Craving
}

\author{
Jean Terrier ${ }^{1,2}$, Christian Lüscher ${ }^{*, 1,2}$ and Vincent Pascoli' \\ 'Department of Basic Neurosciences, Medical Faculty, University of Geneva, Geneva, Switzerland; ${ }^{2}$ Clinic of Neurology, Department of Clinical \\ Neurosciences, Geneva University Hospital, Geneva, Switzerland
}

\begin{abstract}
Addiction is a behavioral disease, of which core components can be modeled in rodents. Much evidence implicates drug-evoked synaptic plasticity in cocaine-evoked locomotor sensitization, cue-induced cocaine seeking, and incubation of cocaine craving. However, the type of plasticity evoked by different modalities of cocaine administration (eg contingent vs non-contingent) and its role in reshaping circuit function remains largely elusive. Here we exposed mice to various regimens of cocaine and recorded excitatory transmission onto identified medium-sized spiny neurons (MSN, expressing fluorescent proteins under the control of either DIR or D2R dopamine receptor promotor) in the nucleus accumbens at time points when behavioral adaptations are observed. In DI-MSN, we found the presence of GluA2-lacking $\alpha$-amino-3-hydroxy-5-methyl-4-isoxazolepropionic acid receptors (AMPARs) after single or chronic non-contingent exposure to cocaine as well as after cocaine self-administration (SA). We also report an increase in the AMPA/NMDA ratio (A/N) in DI-MSN, which was observed only after repeated passive injections associated with locomotor sensitization as well as in a condition of SA leading to seeking behavior. Remarkably, insertion of GluA2-lacking AMPARs was also detected in D2-MSN after SA of a high dose of cocaine but not regular dose ( $1.5 \mathrm{vs} 0.75 \mathrm{mg} / \mathrm{kg}$ ), which was the only condition where incubation of cocaine craving was observed in this study. Moreover, synapses containing GluA2-lacking AMPARs belonged to amygdala inputs in D2-MSN and to medial prefrontal cortex inputs in DI-MSN. Taken together this study allows for a refinement of a circuit model of addiction based on specific synaptic changes induced by cocaine.

Neuropsychopharmacology (2016) 4I, I779-I789; doi:I0.I038/npp.20 I5.345; published online 9 December 2015
\end{abstract}

\section{INTRODUCTION}

Addiction is increasingly recognized as a synaptic disease (Lüscher and Malenka, 2011; Nestler, 2013). Indeed, addictive drugs cause long-lasting modifications of excitatory synaptic transmission to dopamine (DA)-sensitive cells such as medium-sized spiny neurons (MSN) of the nucleus accumbens (NAc) (Wolf and Ferrario, 2010). Such drugevoked synaptic plasticity has been causally linked to drug-adaptive behavior (Lüscher, 2013). For example, pharmacological blockade of AMPAR ( $\alpha$-amino-3-hydroxy5-methyl-4-isoxazolepropionic acid receptor) transmission before cocaine challenge blocks sensitization (Pierce et al, 1996). Additionally, enhanced AMPAR transmission has been observed (Boudreau, 2005) and restoring baseline transmission abolishes locomotor sensitization (Pascoli et al, 2011) and cue-induced seeking (Pascoli et al, 2014). To understand how circuit function is altered to cause the

*Correspondence: Professor C Luscher, Basic Neurosciences, Unige, I Michel Servet, Geneva 1211, Switzerland, Tel: +4I 2237965444, E-mail: christian.luscher@unige.ch

Received 6 August 2015; revised 15 October 2015; accepted 23 October 2015; accepted article preview online 20 November 2015 adaptive behavior, a comprehensive description of the expression mechanism of drug-evoked synaptic plasticity is required.

Many forms of drug-evoked synaptic plasticity involve a redistribution of AMPARs. AMPARs are composed of four subunits, GluA1 to GluA4. The GluA2 subunit, present at most synapses in the adult brain, has an arginine residue located in the pore region of the channel that limits the flow of monovalent ions and prevents the flow of bivalent ions, such as $\mathrm{Ca}^{2+}$. As a result the current-voltage $(I-V)$ curve is linear (Liu and Zukin, 2007). By contrast, GluA2-lacking AMPARs typically assembled from four GluA1 subunits are calcium permeable and have a nonlinear, inward-rectifying $I-V$ curve. In addition to strengthen the synapse GluA2lacking AMPARs may alter the rules of synaptic plasticity, since the calcium influx is particularly strong at negative potentials (Mameli et al, 2011).

Canonical, GluA2-containing AMPARs are inserted at the surface of MSN after few days of withdrawal from a regimen of passive cocaine injections and remain present for at least 21 days (Boudreau, 2005; Kourrich et al, 2007). By contrast, following self-administration (SA) GluA2-lacking AMPARs appear (Conrad et al, 2008; Mameli et al, 2009; Ortinski et al, 
2012; Pascoli et al, 2014) and strengthen excitatory transmission specifically onto D1-MSN (Pascoli et al, 2014). However, some data suggest the possibility that GluA2lacking AMPARs could contribute to cocaine-induced locomotor sensitization since an increase in GluA1 but not GluA2 subunit surface expression on WD 14-21 (Boudreau et al, 2007) has been detected and inwardly rectifying AMPAR-excitatory postsynaptic currents (EPSCs) after extended withdrawal found (Mameli et al, 2009) in MSN of passively injected young mice.

GluA2-lacking AMPARs in the NAc core and shell have been associated with incubation of cocaine craving (Conrad et al, 2008; Lee et al, 2013; Ma et al, 2014; Mccutcheon et al, 2011), referring to the observation that cocaine seeking induced by re-exposure to drug-associated cues progressively increases over the first 2 months of withdrawal (Gawin et al, 1989; Grimm et al, 2001; Pickens et al, 2011). GluA1 subunits appear at the cell surface along with rectifying $I-V$ relationship after prolonged withdrawal period (30-45 days) and pharmacological blockade of GluA2-lacking AMPARs suppresses the 'incubated part of seeking' (Conrad et al, 2008). Further experiments implicate GluA2-lacking AMPARs at BLA or medial prefrontal cortex (mPFC) inputs in the incubation of cocaine craving and in the relapse to cueinduced cocaine seeking, respectively (Lee et al, 2013; Ma et al, 2014). GluA2-lacking AMPARs at mPFC synapses may also mediate altered action-outcome prediction after cocaine SA (Pascoli et al, 2014).

GluA2-lacking AMPARs are implicated in various forms of adaptive behavior, yet several crucial questions remain. Does their appearance in neurons of the NAc require contingent drug exposure? Which role does the dose and duration of cocaine exposure play? The fact that many studies have been carried out without identification of the accumbal cell type may contribute to the lack of consensus. We decided to address these questions by studying cocaine-evoked synaptic plasticity in identified MSN following several conditions of cocaine exposure, both non-contingent (1 or 5 injections) and contingent (short access to a regular dose and then long access to a regular or high dose of cocaine). In parallel, we tested for behavioral sensitization, cue-induced relapse to cocaine seeking and incubation of cocaine craving.

Our data indicate that GluA2-lacking AMPARs are present at D1R-expressing MSN synapses after withdrawal from both contingent and non-contingent cocaine exposure, and appear at BLA to D2R-MSN synapses with higher doses of cocaine SA, when incubation of cocaine craving is observed.

\section{MATERIALS AND METHODS}

\begin{abstract}
Animals
Mice were adult (between P60 and P90 at the beginning of experiments) $\mathrm{C} 57 \mathrm{BL} / 6$ or heterozygous $\mathrm{BAC}$ transgenic mice in which tomato expression was driven by D1R (DrdlatdTomato from Jackson Laboratories) gene regulatory elements or eGFP driven by D2R (Drd2-eGFP from GENSAT) gene regulatory elements. Males and females were used. Transgenic mice had been back-crossed in the C57BL/6 line. Mice were single housed after surgery. All animals were kept in a temperature- and humidity-controlled environment with a $12 \mathrm{~h}$ light $/ 12 \mathrm{~h}$ dark cycle (lights on at $0700 \mathrm{~h}$ ). All
\end{abstract}

procedures were reviewed by the Institutional Animal Care and Use Committee of the University of Geneva and approved by the cantonal veterinary authority.

\section{Surgery}

Jugular vein catheter. Methods for implantation of the jugular catheter in mice was carried out as previously described (Pascoli et al, 2014). Mice were anesthetized with a mixture of ketamine $(60 \mathrm{mg} / \mathrm{kg}$, Ketalar) and xylazine (12 mg/kg, Rompun) solution. Catheters (CamCaths; model MIVSA) made of silicone elastomer tubing (outside diameter $0.63 \mathrm{~mm}$, inside diameter $0.30 \mathrm{~mm}$ ) were inserted $1.0-1.2 \mathrm{~cm}$ in the right jugular vein, about $5 \mathrm{~mm}$ from the pectoral muscle, to reach the right atrium. Mice were allowed to recover for 3-5 days before the start of drug SA training. Catheters were flushed daily with a heparin solution (Heparin 'Bichsel') in saline (30 IU) during the recovery period and just before and after each SA session.

Stereotaxic infusions. Adeno-associated virus AAV5-CamKII-ChR2(H134R)-eYFP produced at the University of North Carolina (Vector Core Facility) was injected into the mPFC or the BLA of 5- to 6-week-old mice. Anesthesia was induced at $5 \%$ and maintained at $2.5 \%$ isoflurane $(\mathrm{w} / \mathrm{v})$ (Baxter AG) during the surgery. The animal was placed in a stereotaxic frame (Angle One) and craniotomies were performed using stereotaxic coordinates (for mPFC: anterior-posterior $(\mathrm{AP}):+1.9$, medial-lateral $(\mathrm{ML}): \pm 0.3$, dorsalventral (DV): -2.5 ; for BLA: AP $-1.4, \mathrm{ML} \pm 3.0, \mathrm{DV}-3.8$ ). Injections of virus $(0.5 \mu \mathrm{l})$ were delivered using graduated pipettes (Drummond Scientific Company), broken back to a tip diameter of $10-15 \mu \mathrm{m}$, at an infusion rate of $0.05 \mu \mathrm{l} / \mathrm{min}$.

\section{Behavioral Testing}

Locomotor sensitization. Locomotor activity was measured as the number of quarter turns entirely crossed by a mouse in a circular corridor. A locomotor chamber apparatus was placed under a video tracking system (Anymaze; Stoelting) and measurements were made automatically. After three daily $1 \mathrm{~h}$ session to habituate the mice to the test apparatus, the animals were injected with saline or cocaine $(20 \mathrm{mg} / \mathrm{kg}$, i.p., $10 \mathrm{ml} / \mathrm{kg})$ immediately before being placed in the corridor. Experimental conditions consisted in one or five sessions of $60 \mathrm{~min}$ followed by a cocaine challenge, 1 week or 10 days later, respectively.

Drug SA acquisition. All behavioral experiments were performed during the light phase and took place in mouse operant chambers (ENV-307A-CT; Med Associates) situated in a sound-attenuating cubicle (Med Associates). Two retractable levers were present on both sides of one wall of the chamber. A cue-light was located above each lever and a house light was present in each chamber. During intravenous drug SA sessions, the stainless steel tubing of the catheter device was connected through a CoEx PE/PVC tubing (BCOEX-T25; Instech Solomon) to a swivel (Instech Solomon) and then an infusion pump (PHM-100; MedAssociates). The apparatus was controlled and data captured using a PC running MED-PC IV (Med-Associates). 
Each session was 120 min in duration for the short access condition and $360 \mathrm{~min}$ for the long-access conditions and started with the illumination of the house light and the insertion of the two levers into the operant chamber. During 10 sessions, a single press on the active lever resulted in an infusion of $0.75 \mathrm{mg} / \mathrm{kg}$ or $1.5 \mathrm{mg} / \mathrm{kg}$ of cocaine (cocaine hydrochloride, provided by the pharmacy of Geneva University Hospital, dissolved in $0.9 \%$ saline at $0.75 \mathrm{mg} / \mathrm{ml}$ and delivered at $0.0177 \mathrm{ml} / \mathrm{s}$ as a unit dose depending on the weight of the mouse) paired with 10 flashes of $1 \mathrm{~s}$ duration of the cue light above the active lever. Rewarded lever press triggers a timeout period of $40 \mathrm{~s}$ during which cocaine was no longer available. The active lever (left or right lever) was randomly assigned for each mouse. To avoid an overdose of cocaine, a maximum of 45 infusions were allowed per session for the short access, 100 infusions for the $0.75 \mathrm{mg} / \mathrm{kg}$ long access, and 50 infusions for the $1.5 \mathrm{mg} / \mathrm{kg}$ long access. Saline control mice undertook the same procedure as cocaine mice except that saline $(\mathrm{NaCl} 0.9 \%$ B. Braun) replaced cocaine infusions. After acquisition, mice were randomly attributed to either behavior or electrophysiology experiments.

Cue-induced cocaine-seeking test. Tests took place 1 day and 30 days after the final SA session. Mice underwent both sessions (within subject protocol). The cue-induced drugseeking test was a 60-min session, identical to the saline or cocaine acquisition procedure (presence of the same cuelight with the same duration (10 s), insertion of the two levers), except that one press on the active lever now triggered illumination of the cue light but infusion was omitted. Pump noise was maintained.

\section{Slice Electrophysiology}

Coronal $200-250 \mu \mathrm{m}$ slices of mouse brain were prepared in cooled artificial cerebrospinal fluid containing (in $\mathrm{mM}$ ): $\mathrm{NaCl} 119, \mathrm{KCl} 2.5, \mathrm{MgCl} 1.3, \mathrm{CaCl}_{2} 2.5, \mathrm{Na}_{2} \mathrm{HPO}_{4}$ 1.0, $\mathrm{NaHCO}_{3} 26.2$, and glucose 11 , bubbled with $95 \% \mathrm{O}_{2}$ and $5 \%$ $\mathrm{CO}_{2}$. Slices were kept at $32-34{ }^{\circ} \mathrm{C}$ in a recording chamber superfused with $2.5 \mathrm{ml} / \mathrm{min}$ artificial cerebrospinal fluid. The visualized whole-cell voltage-clamp recording technique was used to measure holding and synaptic responses of MSNs of the NAc shell, identified by the presence of the eGFP or tdTomato of BAC transgenic mice by using a fluorescent microscope (Olympus BX50WI; fluorescent light U-RFL-T). The holding potential was $-70 \mathrm{mV}$, and the access resistance was monitored by a hyperpolarizing step of $14 \mathrm{mV}$ in each $10 \mathrm{~s}$ sweep. The liquid junction potential was small $(3 \mathrm{mV})$, and therefore traces were not corrected. Experiments were discarded if the access resistance varied by more than $20 \%$. Currents were amplified (Multiclamp 700B; Axon Instruments), filtered at $5 \mathrm{kHz}$, and digitized at $20 \mathrm{kHz}$ (National Instruments Board PCI-MIO-16E4, Igor; WaveMetrics). All experiments were performed in the presence of picrotoxin $(100 \mu \mathrm{M})$. For recordings of electrically evoked EPSCs, the internal solution contained (in $\mathrm{mM}$ ) $130 \mathrm{CsCl}, 4 \mathrm{NaCl}, 5$ creatine phosphate, $2 \mathrm{MgCl}_{2}, 2 \mathrm{NA}_{2} \mathrm{ATP}, 0.6 \mathrm{NA}_{3} \mathrm{GTP}, 1.1$ EGTA, 5 HEPES, and $0.1 \mathrm{~mm}$ spermine. For optogenetic EPSCs, QX-314 $(5 \mu \mathrm{M})$ was added to the solution to prevent action currents. Synaptic currents were electrically evoked by stimuli $(50-100 \mu \mathrm{s}, 2-5 \mathrm{~V})$ at $0.1 \mathrm{~Hz}$ through a bipolar stainless tungsten electrode (MX21CEW(CL1), FHC) placed onto the tissue, at a minimal distance of $200 \mu \mathrm{m}$ from the recorded cell. To isolate AMPAR-evoked EPSCs, the NMDA antagonist D-AP5 $(50 \mu \mathrm{M})$ was bath applied. The NMDAR component was calculated as the difference between the EPSCs measured in the absence and in the presence of D-AP5. The AMPAR/NMDAR ratio was calculated by dividing the peak amplitudes. The rectification index of AMPAR was calculated as the ratio of the chord conductance calculated at negative potential divided by chord conductance at positive potential. Note that, in example traces, stimulation artifact was removed. For optogenetic experiments, EPSCs were evoked with $4 \mathrm{~ms}$ blue light pulses from an optic fiber directed at the tissue that was coupled to a DPSS blue light laser.

\section{Imaging}

Mice infected with ChR2 in the mPFC or BLA or vHipp (see above) were used for electrophysiological recordings but thinner sections $(50 \mu \mathrm{m})$ were kept for imaging of the infection site. Slices were placed in paraformaldehyde in $0.1 \mathrm{M}$ sodium phosphate buffer $(\mathrm{pH} 7.5)$ for $2 \mathrm{~h}$ at $4{ }^{\circ} \mathrm{C}$. Images of brain slices from $\mathrm{mPFC}$ and BLA were obtained using sequential laser scanning confocal microscopy (Zeiss LSM510 META). Photomicrographs were obtained with the following bandpass and long-pass filter settings: GFP (bandpass filter: 505-530). The objectives and the pinhole setting (1 airy unit) remained unchanged during the acquisition of a series for all images. The thickness of the optical section is $\sim 6 \mu \mathrm{m}$ with a $\times 10$ objective. Images were aligned using PTGui software.

\section{Statistical Analysis}

All data are presented as mean \pm SEM. Multiple comparisons were first subject to mixed-factor ANOVA defining both between- and/or within-group factors. Where significant main effects or interaction terms were found, further comparisons were made by a two-tailed Student's $t$-test with Bonferroni corrections applied when appropriate (ie the level of significance equaled 0.05 divided by the number of comparisons). Single comparisons of between- or withingroup measures were made by two-tailed non-paired or paired Student's $t$-test, respectively.

\section{RESULTS}

\section{Cocaine-Evoked Synaptic Plasticity after Acute or Chronic Non-Contingent Injection}

We first evaluated excitatory transmission in the NAc shell 7-10 days after non-contingent intraperitoneal (i.p.) injections of cocaine. Mice receive a single exposure or five chronic daily injections of cocaine $20 \mathrm{mg} / \mathrm{kg}$ or saline immediately before locomotor recordings (Figure 1a). As previously shown (Pascoli et al, 2011; Valjent et al, 2006), both type of cocaine regimens are sufficient to induce locomotor sensitization, an increased (Student's $t$-test: $t_{(48)}=3.624, P<0.001$ and $t_{(23)}=5.335, P<0.0001$, for $1 \times$ and $5 \times$, respectively) locomotor response to a cocaine challenge 7-10 days later (Figure 1b). The AMPA/NMDA ratio $(\mathrm{A} / \mathrm{N})$, an electrophysiological evaluation of the 
a

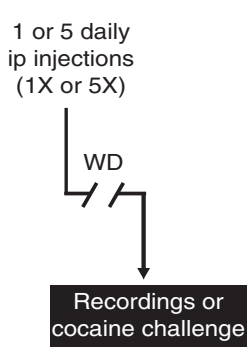

d
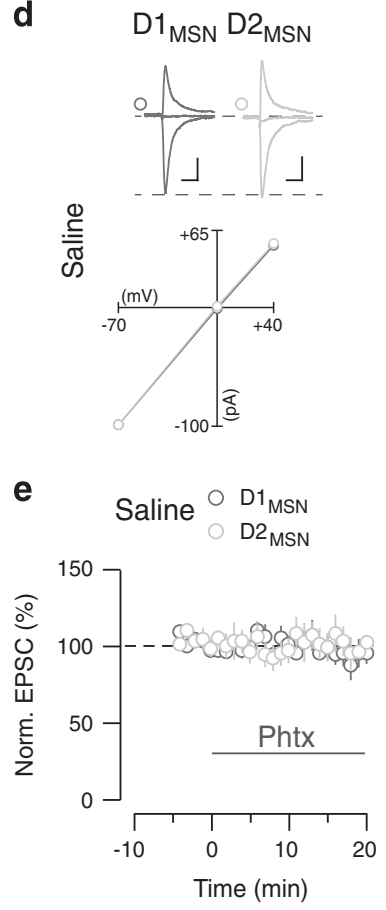

b

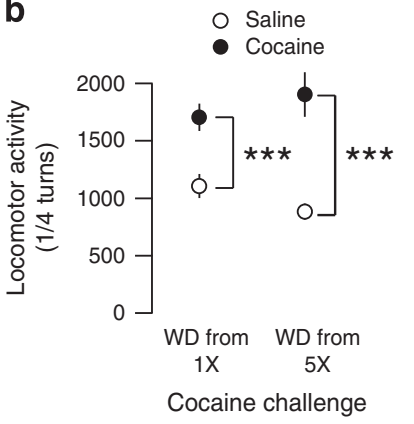

C

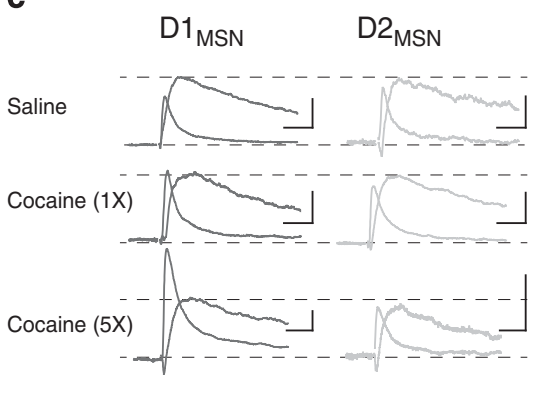

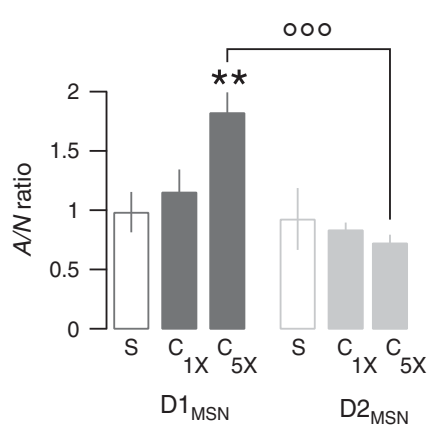

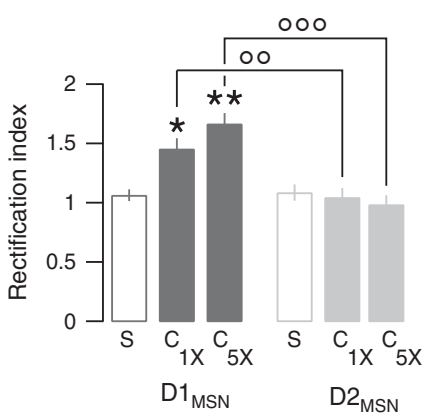

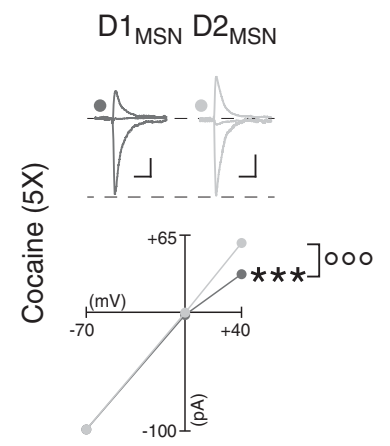
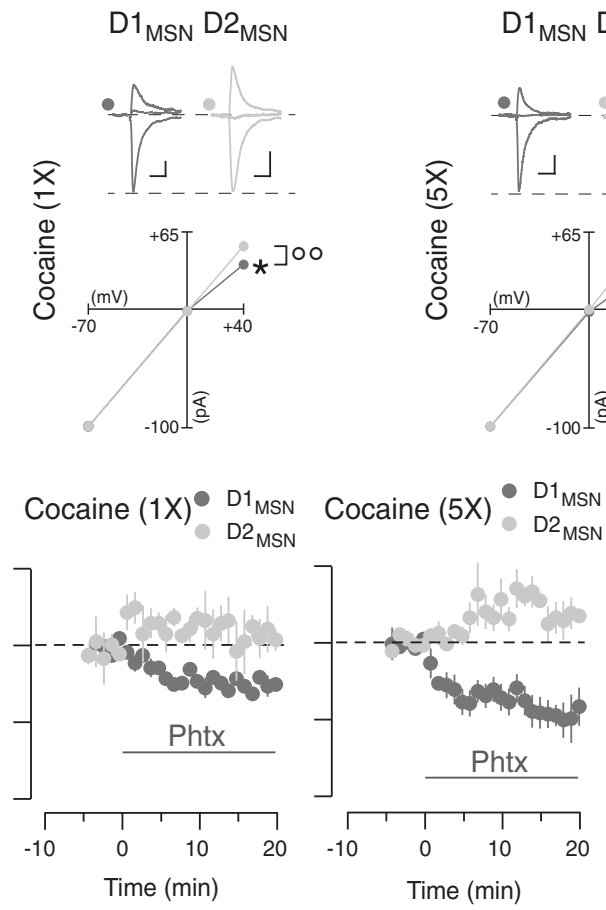

f
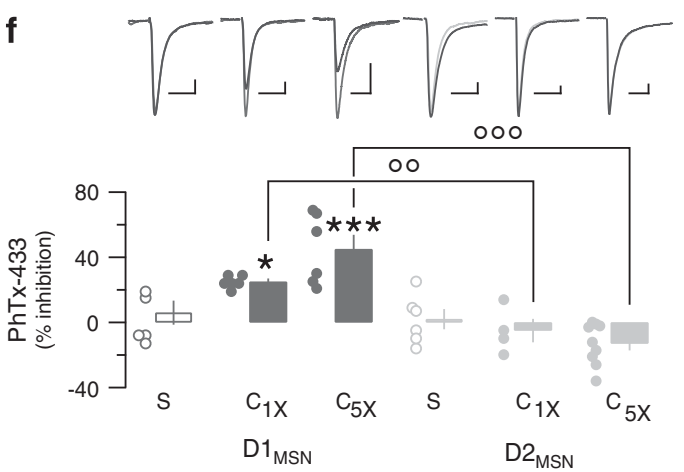

Figure I GluA2-lacking AMPARs present after non-contingent injection of cocaine. (a) Schematic of experiment. (b) Acute challenge of cocaine (20 mg/kg, i.p., $10 \mathrm{ml} / \mathrm{kg}$ ) after withdrawal induced a sensitized response in mice previously injected one or five times daily with cocaine $(I \times$ or $5 \times)$ when compared with saline condition ( $N=1$ I-29 mice). Student's t-test: **** $P<0.00$ I. (c) Example traces (average of I $5-20$ sweeps) of AMPAR and NMDAR-EPSCs recorded at $+40 \mathrm{mV}$ in DI and D2-MSN in slices from the NAc shell 7-10 days after saline, cocaine $1 \times$, or $5 \times$. Quantification of AMPAR/NMDAR ratio (A/N) for each condition ( $N=4-9$ cells from 8 saline, I 0 coc. I $\times$, and II coc $5 \times$ treated mice). Bonferroni post-test $* * P<0.01$, for cocaine vs saline and ${ }^{\circ 00} P<0.00$ I for $\mathrm{DI}$ vs D2. (d) Example traces of AMPA-EPSCs recorded at $-70,0$, and $+40 \mathrm{mV}, 1-V$ relationship and quantification of the rectification index (RI) in DI-MSN and D2-MSN after cocaine I $\times$ or $5 \times(N=5-15$ cells from from 8 sal., 10 coc. I $\times$, and I I coc. $5 \times$ treated mice). Bonferroni post-test $* P<0.05$, $* * P<0.0$ I, or ${ }^{*} * * P<0.00$ I, for cocaine vs saline and ${ }^{\circ 0} \mathrm{P}<0.0$ I or ${ }^{\circ 00} \mathrm{P}<0.00$ I for DI vs D2. (e) Normalized amplitude of AMPAR-EPSCs (points are average of 6 sweeps) at $-70 \mathrm{mV}$ with bath application of the selective inhibitor of GluA2-lacking AMPARs philantotoxin (Phtx-433, $2 \mu \mathrm{M}$ ) in function of time. (f) Example traces of AMPAR-EPSCs before and after philantotoxin and scatter plot of percentage inhibition of AMPAR-EPSCs for each recorded neuron. Decrease of AMPAR-EPSCs amplitude was observed in DI-MSN for cocaine I $\times$ or $5 \times(N=4-9$ cells from 7 sal., 4 coc. I $\times$, and 6 coc. $5 \times)$. Bonferroni post-test * $P<0.05$ or ${ }^{*} * * P<0.00$ I, for cocaine vs saline and ${ }^{\circ} \mathrm{P}<0.0$ I or ${ }^{000} \mathrm{P}<0.00$ I for D I vs D2. Note that for electrophysiological data, cells from saline I $\times$ and $5 \times$ treated mice were pooled. Scale bars, $20 \mathrm{~ms}, 20 \mathrm{pA}$. Data are expressed as mean \pm SEM. AMPAR, $\alpha$-amino-3-hydroxy-5-methyl-4-isoxazolepropionic acid receptor; EPSC, excitatory postsynaptic current; I-V, current-voltage; MSN, medium-sized spiny neuron; NAc, nucleus accumbens; NMDAR, N-methyl-Daspartate receptor.

strength of excitatory transmission, was recorded from D1 and D2-MSN using Drd1a-tdTomato or Drd2-EGFP BAC transgenic mice. Compared with the saline control-injected mice the $\mathrm{A} / \mathrm{N}$ ratio was significantly higher in D1-MSN from mice exposed to five cocaine injections $(5 \times)$ but not from mice exposed to the single injection $(1 \times)$ (mixed two-way ANOVA: cell-type effect, $F_{(1,44)}=12.19, P=0.0011$; treatment effect, $F_{(2,44)}=2.32$, n.s.; cell-type $\times$ treatment, $\left.F_{(2,44)}=4.64, P=0.0149\right)$. This indicates a strengthening of the synaptic transmission selectively onto D1-MSN (Bonferroni post-test: $t_{(13)}=3.598, P<0.01$, for cocaine $5 \times v s$ saline and $t_{(23)}=4.947, P<0.001$, for D1 vs D2-MSN). In slices from the same animals, we next analyzed the $I-V$ curve of the AMPAR transmission in D1R and D2R-MSN (Figure 1c). When exposed to saline the curve was linear and the rectification index therefore had a value of 1 , in both $\mathrm{D} 1$ and D2-MSN. GluA2-lacking AMPARs were detected in D1-MSN from mice injected with a single or five doses, but 

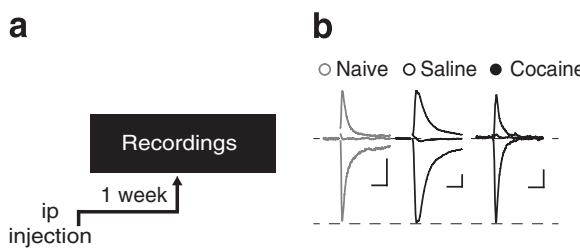

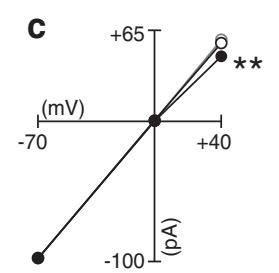

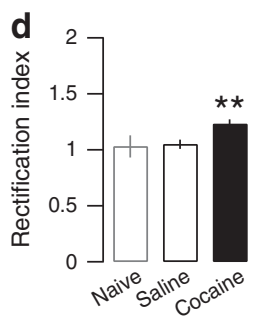

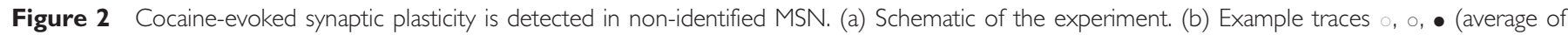

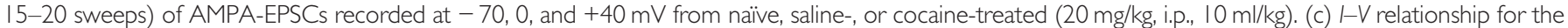

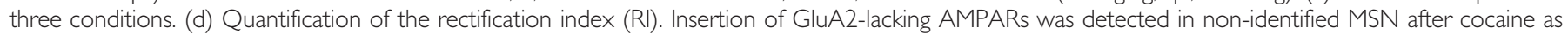

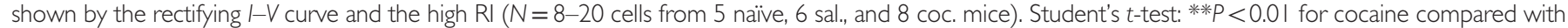

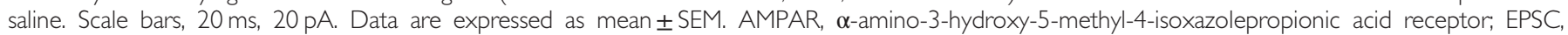
excitatory postsynaptic current; I-V, current-voltage; MSN, medium-sized spiny neuron.

not in D2-MSN, as shown by the rectifying $I-V$ relationship (mixed two-way ANOVA for normalized EPSCs amplitude at $+40 \mathrm{mV}$ : cell-type effect, $F_{(1,44)}=24.81, P<0.0001$; treatment effect, $F_{(2,44)}=2.92, P=0.065$; cell type $\times$ treatment, $F_{(2,44)}=5.681, P=0.0064$; Bonferroni post-test: $t_{(13)}=2.921$, $P<0.05$ for coc. $1 \times$ vs sal.; $t_{(19)}=4.39, P<0.001$ for coc. $5 \times$ vs sal.; $t_{(15)}=3.304, P<0.01$ and $t_{(20)}=5.934, P<0.001$, for D1 vs D2-MSN after coc. $1 \times$ and $5 \times$, respectively) and the rectification index (mixed two-way ANOVA: cell-type effect, $F_{(1,44)}=20.18, P<0.0001$; treatment effect, $F_{(2,44)}=3.14, P=0.0531$; cell-type $\times$ treatment, $F_{(2,44)}=6.205$, $P=0.0042$. Bonferroni post-test: $t_{(13)}=2.839, P<0.05$ for coc. $1 \times$ vs sal.; $t_{(19)}=4.732, P<0.001$ for coc. $5 \times$ vs sal.; $t_{(15)}=3.252, P<0.01$ and $t_{(20)}=5.617, P<0.001$, for D1 vs D2-MSN after coc. $1 \times$ and $5 \times$, respectively) (Figure $1 c$ ). We further confirmed this change in AMPAR subunit composition evoked by cocaine in D1R-MSN using the pharmacological inhibition of the AMPAR-mediated EPSCs with philantotoxin (Phtx-433), a selective inhibitor of GluA2lacking AMPARs (Figure 1e and $\mathrm{f}$ ). The amplitude of the AMPAR-EPSCs in D1R-MSN was significantly (mixed twoway ANOVA: cell-type effect, $F_{(1,29)}=36.56, \quad P=0.0003$; treatment effect, $F_{(2,29)}=0.985$, n.s.; cell-type $\times$ treatment, $\left.F_{(2,29)}=10.07, P<0.001\right)$ decreased after application of Phtx433 in mice exposed to cocaine $1 \times$ or $5 \times$ (Bonferroni posttest: $t_{(9)}=2.376, P<0.05$ for coc. $1 \times v s$ sal.; $t_{(10)}=4.113$, $P<0.001$ for coc. $5 \times$ vs sal.; $t_{(7)}=3.242, P<0.01$ and $t_{(12)}=7.177, P<0.001$, for D1 vs D2-MSN after coc. $1 \times$ and $5 \times$, respectively). Taken together these data are in line with the previously reported increased amplitude of miniature EPSCs selectively onto D1R-MSN (Pascoli et al, 2011). These data indicate that non-contingent cocaine exposure is sufficient to change the AMPAR subunit composition in the subpopulation of MSN expressing the D1 receptor that may contribute to the synaptic potentiation, because GluA2lacking AMPARs have a higher single channel conductance than GluA2-containing AMPARs (Jonas and Burnashev, 1995; Liu and Zukin, 2007; Verdoorn et al, 1991).

These experiments also demonstrate the power of cell-type identification, because in a separate series of experiments without cell-type identification it took many cells to reveal a significant decrease of AMPAR-mediated current at positive potential (Figure 2a-e). Indeed, in non-identified MSN population of the NAc shell from mice exposed to cocaine, the change in RI was diluted and a small, but a significant increase (Student's $t$-test: $t_{(36)}=3.087, \quad P=0.0039$ and $t_{(36)}=3.350, \quad P=0.0019$, for normalized AMPAR-EPSCs amplitude at $+40 \mathrm{mV}$ and $\mathrm{RI}$, respectively) was observed (Figure 2). In addition, no change in AMPAR subunit composition in MSN was found in saline-treated mice when compared with naïve animals (Figure $2 \mathrm{a}-\mathrm{d}$ ).

\section{GluA2-Lacking AMPARs after Withdrawal from Short Access to Cocaine SA}

We next evaluated change in excitatory transmission following withdrawal from contingent administration of cocaine. To this aim, a group of mice was trained to selfadminister cocaine ( $0.75 \mathrm{mg}$ cocaine/ $\mathrm{kg} /$ infusion) for $2 \mathrm{~h} /$ day for 10 days. A month later mice were submitted to a cueinduced cocaine-seeking session of $1 \mathrm{~h}$ during which the infusion pump was not connected to the catheter. A different cohort of mice was used for electrophysiological recordings (Figure 3a). Mice that previously had self-administered cocaine showed a cue-induced cocaine-seeking behavior by pressing the active lever (mixed two-way ANOVA for matched data: lever effect, $F_{(1,26)}=9.873, P=0.0042$; treatment effect, $F_{(1,26)}=59.2, \quad P<0.0001$; lever $\times$ treatment, $F_{(1,26)}=9.764, P=0.0043$; Bonferroni post-test: $t_{(13)}=7.65$, $P<0.001$ for coc. $v s$ sal. and $t_{(13)}=3.231, P<0.01$ for coc. $v s$ sal. at active and inactive lever, respectively; $t_{(5)}=4.746$, $P<0.001$ for active $v s$ inactive lever in cocaine-treated mice) (Figure 3b). At the same time, electrophysiological recordings ex vivo showed a significantly increased $\mathrm{A} / \mathrm{N}$ ratio in D1-MSN but not in D2-MSN (mixed two-way ANOVA: cell-type effect, $F_{(1,26)}=13.3, P=0.0012$; treatment effect, $F_{(1,26)}=7.55, P=0.0108$; cell type $\times$ treatment, $F_{(1,26)}=6.358$, $P=0.0182$; Bonferroni post-test: $t_{(13)}=3.726, P<0.001$ for coc. vs sal.; $t_{(16)}=4.877, P<0.001$ for D1 vs D2-MSN after cocaine) (Figure 3c). Similarly, rectifying $I-V$ relationship (mixed two-way ANOVA for normalized EPSCs amplitude at $+40 \mathrm{mV}$ : cell-type effect, $F_{(1,26)}=1.202$, n.s.; treatment effect, $F_{(1,26)}=3.452$, n.s.; cell type $\times$ treatment, $F_{(1,26)}=5.086$, $P=0.0328$; Bonferroni post-test: $t_{(13)}=2.908, \stackrel{P}{P}<0.05$ for coc. vs sal.; $t_{(16)}=2.65, P<0.05$ for D1 vs D2-MSN after cocaine) and increased RI (mixed two-way ANOVA: cell-type effect, $\quad F_{(1,26)}=5.899, \quad P=0.0224$; treatment effect, $\quad F_{(1,26)}=10.19, \quad P=0.0037$; cell type $\times$ treatment, $F_{(1,26)}=8.769, P=0.0065$; Bonferroni post-test: $t_{(13)}=4.351$, $P<0.001$ for coc. vs sal.; $t_{(16)}=4.261, P<0.001$ for D1 vs D2MSN after cocaine) were again detected selectively in D1-MSN (Figure 3d) and confirmed by an increased 


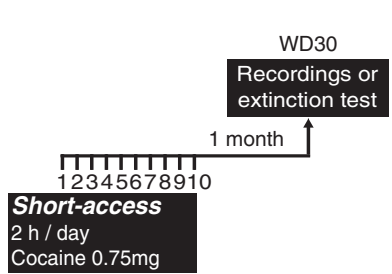

b

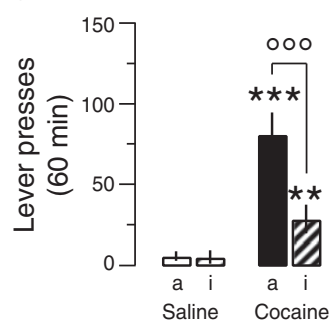

C

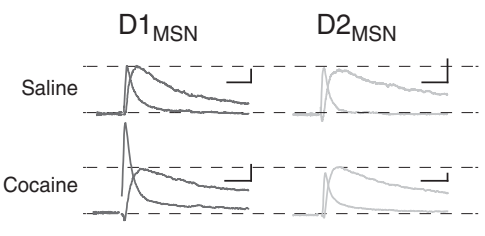

d

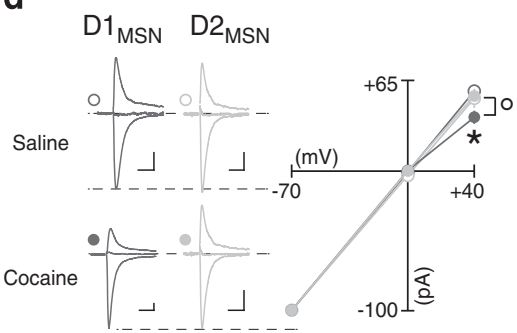

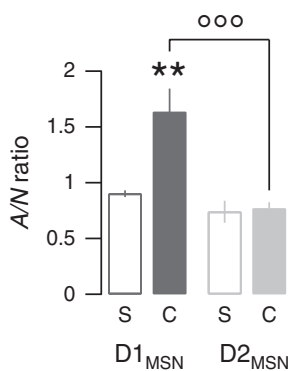
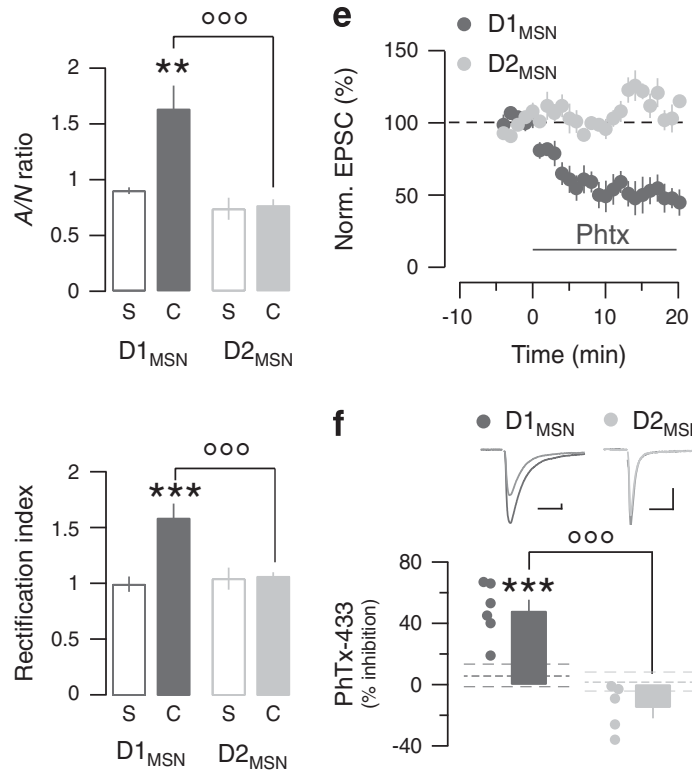

f

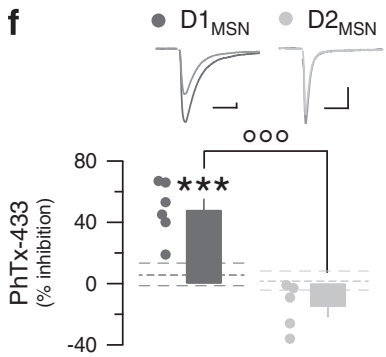

Figure 3 Short access to cocaine self-administration leads to cue-induced cocaine seeking and insertion of GluA2-lacking AMPARs after withdrawal. (a) Schematic of the experiment. (b) Active a and inactive i lever presses for both saline and cocaine conditions during the I h cue-induced cocaine-seeking session performed at WD30 ( $N=6-9$ mice). Bonferroni post-test $* * P<0.0$ I or *** $P<0.00$ I, for cocaine vs saline and ${ }^{\circ 00} P<0.00$ I for active vs inactive lever. (c) Example traces of AMPAR and NMDAR-EPSCs recorded at $+40 \mathrm{mV}$ in DI and D2R-MSN in slices from the NAc shell 30 days after saline or cocaine selfadministration. Quantification of the AMPAR/NMDAR ratio (A/N) ( $N=6-9$ cells from 9 sal. and I 2 coc.). Bonferroni post-test *** $P<0.00$ I, for cocaine $v s$ saline and ${ }^{000} \mathrm{P}<0.000 \mathrm{I}$ for DI vs D2. (d) Example traces of AMPAR-EPSCs recorded at $-70,0$, and $+40 \mathrm{mV}, I-V$ relationship and quantification of the rectification index (RI) ( $N=6-9$ cells from 9 sal. and 12 coc.). Bonferroni post-test $* P<0.05$ or $* * * P<0.00$ I, for cocaine vs saline and ${ }^{\circ} P<0.05$ or ${ }^{\circ 00}$ $P<0.00$ I for DI vs D2. (e) Normalized AMPAR-EPSCs in function of time (points are average of 6 sweeps), with bath application of philantotoxin (Phtx-433, $2 \mu \mathrm{M})$. ( $\mathrm{f}$ ) Example traces of AMPAR-EPSCs at $-70 \mathrm{mV}$ before and after philantotoxin and percentage of inhibition for each recorded neuron. Decrease of AMPAR-EPSCs amplitude was observed in DI-MSN for cocaine SA ( $N=5-6$ cells from 6 mice). Data for saline are from Figure 2. Bonferroni post-test **** $P<0.00$ I, for cocaine vs saline and ${ }^{000} \mathrm{P}<0.00$ I for DI vs D2. Scale bars, $20 \mathrm{~ms}, 20 \mathrm{pA}$. Data are expressed as mean \pm SEM. AMPAR, $\alpha$-amino-3-hydroxy-5-methyl-4-isoxazolepropionic acid receptor; EPSC, excitatory postsynaptic current; MSN, medium-sized spiny neuron; NAc, nucleus accumbens; NMDAR, N-methyl-D-aspartate receptor.

sensitivity (mixed two-way ANOVA: cell-type effect, $F_{(1,19)}=22.29, P=0.0001$; treatment effect, $F_{(1,19)}=5.284$, $P=0.033$; cell type $\times$ treatment, $F_{(1,19)}=17.79, P=0.0005$; Bonferroni post-test: $t_{(10)}=4.722, P<0.001$ for coc. $v s$ sal.; $t_{(9)}=6.176, P<0.001$ for D1 vs D2-MSN after cocaine) to philantotoxin (Figure $3 e$ and $\mathrm{f}$ ).

A new cohort of mice that underwent two sessions of cueinduced drug-seeking at withdrawal day 1 and 30 (WD30) was prepared, in order to test for incubation of cocaine craving (Figure 4a). This method using within subject comparison had previously been used in rats (Xi et al, 2012). In our direct comparison, the cue-induced cocaine seeking was lower (mixed two-way ANOVA for repeated measures: lever effect, $F_{(1,10)}=12.90, P=0.049$; session effect, $F_{(1,10)}=4.64, \quad P=0.057 ; \quad$ lever $\times$ session, $\quad F_{(1,10)}=1.85$, $P=0.204$; Bonferroni post-test: $t_{(4)}=3.48, P<0.01$ and $t_{(4)}=1.54, P>0.05$ for active $v s$ inactive (WD1 and WD30, respectively); $t_{(5)}=2.48, P>0.05$ and $t_{(5)}=0.56, P>0.05$ for WD1 vs WD30 (active and inactive, respectively); paired Student's $t$-test: $t_{(5)}=2.444, P>0.05$, for relative active lever presses number WD1 vs WD30) on WD30 than WD1 (Figure $4 \mathrm{~b}$ ). In other words, we failed to observe incubation of cocaine craving in a condition of short access to cocaine SA where GluA2-lacking AMPARs were present (see Figure $3 \mathrm{~d}$ and e). In previous studies, locomotor response to psychostimulants have been shown to be equivalent in Drd1a-td-tomato and Drd2-egfp hetererozygous mice and their wild-type littermates (Nelson et al, 2012). However, no such comparison has been made for cocaine SA. In order to control for any confounding effects due to the use of BAC transgenic mouse lines, we directly compared a cohort of Drd1a-td-tomato and Drd2-egfp hetererozygous mice with their wild-type littermates and with C57Bl6J for acquisition of cocaine SA and for cue-induced cocaine seeking after prolonged withdrawal. No statistical difference (mixed twoway ANOVA for repeated measures, for infusions: genotype effect, $F_{(4,155)}=1.77, P=0.14$; session effect, $F_{(9,1395)}=5.19$, $P<0.0001$; genotype $\times$ session, $F_{(36,1395)}=1.45, P=0.042$; for active lever: genotype effect: $F_{(4,155)}=1.26, P=0.29$; session effect, $\quad F_{(9,1395)}=12.48, \quad P<0.0001 ; \quad$ genotype $\times$ session, $F_{(36,1395)}=1.01, P=0.46$; for inactive lever: genotype effect: $F_{(4,155)}=0.94, \quad P=0.44 ; \quad$ session effect, $\quad F_{(9,1395)}=4.12$, $P<0.0001$; genotype $\times$ session, $F_{(36,1395)}=1.01, P=0.45 ; \mathrm{AN}-$ OVA for total cocaine intake between genotype: $F_{(4,155)}=1.78, \quad P=0.14$; ANOVA for lever discrimination between genotype: $F_{(4,155)}=1.53, P=0.20$; for cue-induced cocaine-seeking: mixed two-way ANOVA for infusions: genotype effect, $F_{(4,50)}=0.22, \quad P=0.93$; lever effect, $F_{(1,50)}=130.7, \quad P<0.0001 ;$ genotype $\times$ lever, $\quad F_{(4,50)}=1.07$, $P=0.38$, Bonferroni's post-test: $t_{(9)}=3.61, \quad P<0.01$, $t_{(11)}=7.04, \quad P<0.001, \quad t_{(7)}=4.38, \quad P<0.001, \quad t_{(9)}=4.93$, $P<0.001, t_{(19)}=7.62, P<0.001$ for active $v s$ inactive lever in DrD1a-WT, DrD1a-td-tomato +/-, DrD2-WT, DrD2egfp+/ - and C57Bl6J, respectively) between the different mouse lines was observed during acquisition of cocaine SA or relapse (Supplementary Figure 1). 
a

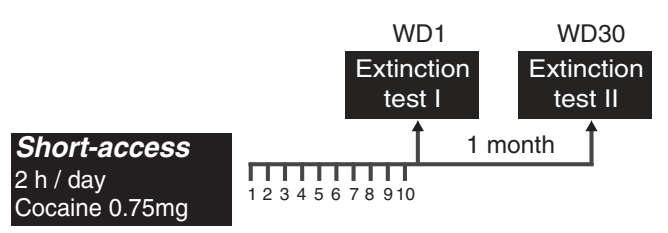

C

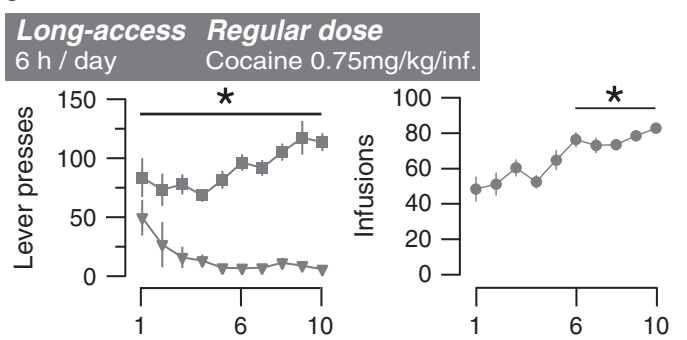

Long-access High dose

$6 \mathrm{~h} /$ day $\quad$ Cocaine $1.5 \mathrm{mg} / \mathrm{kg} / \mathrm{inf}$.
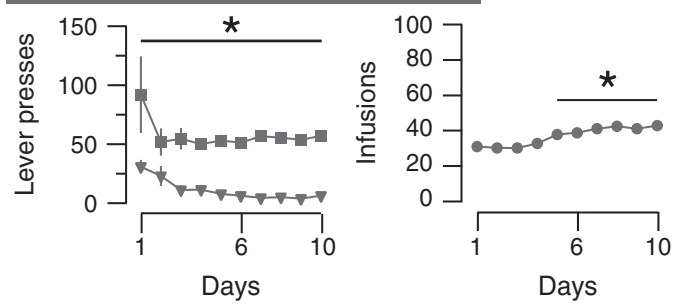

e

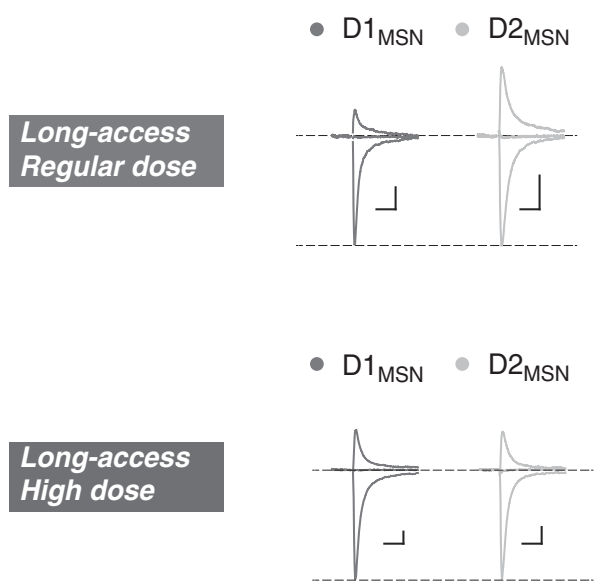

b

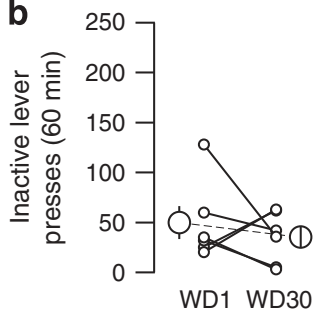

d
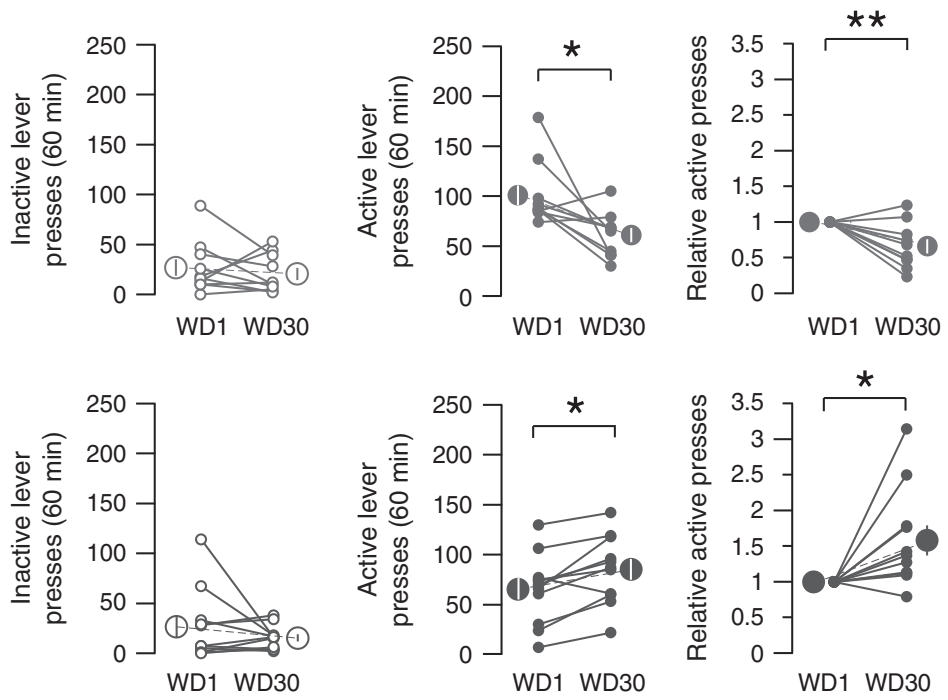
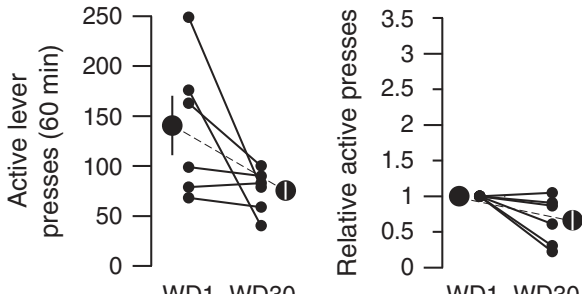

WD1 WD30

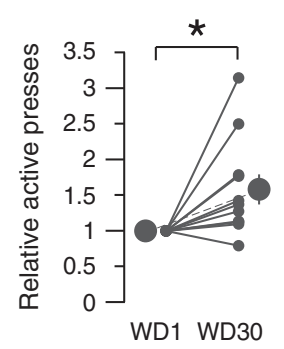

f
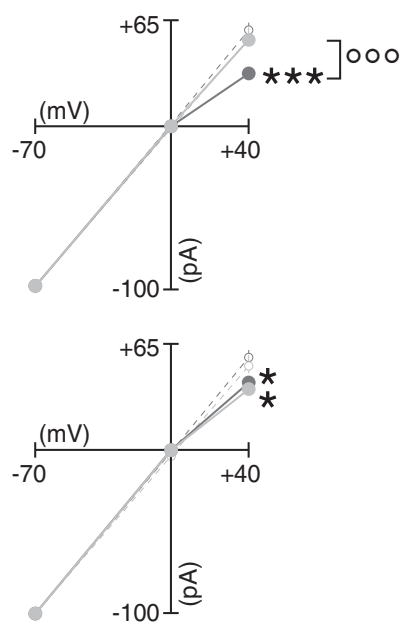
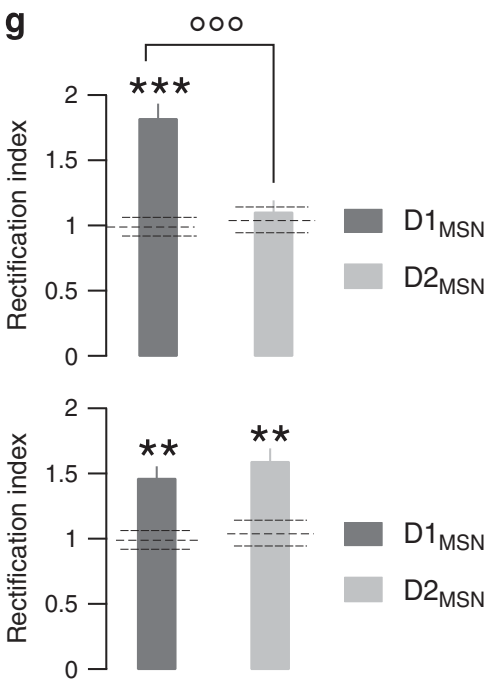

Figure 4 High dose of cocaine induces incubation of cocaine craving and inserts GluA2-lacking AMPARs in D2R-MSN. (a) Schematic of the experiment. (b) Inactive, active lever presses and relative presses are represented for each mouse during cue-induced cocaine-seeking sessions (I h) at withdrawal days I and 30 (WDI and WD30) (bottom) from cocaine SA ( 10 daily sessions of $2 \mathrm{~h}$ with $0.75 \mathrm{mg} / \mathrm{kg} /$ infusion of cocaine) ( $\mathrm{N}=6$ ). (c) Number of infusions (top) and lever presses (active and inactive) during the 10 days of acquisition are represented for mice submitted to long-access sessions ( $6 \mathrm{~h}$ ) with either 0.75 (top) or $1.5 \mathrm{mg} / \mathrm{kg} /$ infusion (bottom) of cocaine ( $N=13-29$ mice). Dunnett's post-test for infusions: $* P<0.01$ when compared with first session; Bonferroni post-test: $* P<0.0$ I for active vs inactive. (d) Individual number of inactive, active lever presses and relative active lever presses during the cue-induced cocaine seeking at WDI and 30. Incubation of cocaine craving was present for the high concentration of cocaine per infusion, but not for the regular concentration $(N=I 0-1 \mathrm{I})$. $* P<0.05$ or $* * P<0.01$ for WD 30 vs WD I. (e) Example traces of AMPAR-EPSCs recorded at -70 , 0 , and $+40 \mathrm{mV}$. (f) I-V relationship for AMPAR-EPSCs in $\mathrm{DI}$ and D2-MSN from regular or high dose of cocaine SA mice $(N=9-17$ cells from 3 and 6 mice, respectively). Bonferroni post-test $* * P<0.0$ I or **** $P<0.00$ I, for cocaine vs saline and ${ }^{000} \mathrm{P}<0.00$ I for DI vs D2. Dashed lines represented values obtained from saline SA in the experiment of Figure 3 . (g) Quantification of the RI for AMPAR-EPSCs in DI and D2-MSN from regular or high dose of cocaine SA mice ( $N=9-17$ cells from 3 and 6 mice, respectively). Bonferroni post-test $* * P<0.0$ I or $* * * P<0.00$ I, for cocaine vs saline and ${ }^{\circ 0} P<0.00$ I for DI vs D2. Dashed lines represented values obtained from saline SA in the experiment of Figure 3. Scale bars, $20 \mathrm{~ms}, 20$ pA. Data are expressed as mean \pm SEM. AMPAR, $\alpha$-amino-3-hydroxy-5-methyl-4isoxazolepropionic acid receptor; EPSC, excitatory postsynaptic current; MSN, medium-sized spiny neuron; SA, self-administration. 


\section{Incubation of Cocaine Craving with a High Dose of Cocaine}

We next asked whether changing the parameters of cocaine SA acquisition could allow observation of the incubation of cocaine-craving phenomenon. Two additional conditions of SA acquisition were tested: long access $(6 \mathrm{~h})$ with the same dose of cocaine than previously used $(0.75 \mathrm{mg} / \mathrm{kg} /$ infusion $)$ and long access with a higher dose $(1.5 \mathrm{mg} / \mathrm{kg} /$ infusion $)$.

Increasing the SA access to $6 \mathrm{~h}$ per session resulted in a high number of infusions of cocaine $0.75 \mathrm{mg} / \mathrm{kg} /$ infusion with an escalation of the intake over the acquisition days (ANOVA for repeated measures: session effect, $\left.F_{(9,129)}=8.299, P<0.0001\right)$ as observed in rats (Ahmed and Koob, 1998; Figure 4c). The mice adapted their lever presses to obtain cocaine infusions with a regular rate and quickly discriminated between the active and inactive lever (mixed two-way ANOVA for matched data: lever effect, $F_{(1,216)}=$ 141.9, $P<0.0001$; session effect, $F_{(9,216)}=1.923, P=0.05$; lever $\times$ session, $\left.F_{(9,216)}=4.363, P<0.0001\right)$. With the dose of cocaine used so far, the cue-induced cocaine-seeking response on WD1 was elevated (around 100 active lever presses in $1 \mathrm{~h}$ ) and slightly decreased on WD30 (Figure 4d). Thus, short or long access to $0.75 \mathrm{mg} / \mathrm{kg}$ of cocaine did not lead to incubation of cocaine craving (mixed two-way ANOVA for repeated measures: lever effect, $F_{(1,18)}=52.93$, $P<0.0001$; session effect, $F_{(1,18)}=8.08, P<0.001$; lever $\times$ session, $\quad F_{(1,18)}=4.19, \quad P=0.055 ; \quad$ Bonferroni post-test: $t_{(9)}=6.52, P<0.001$ and $t_{(9)}=3.58, P<0.01$ for active $v s$ inactive (WD1 and WD30, respectively); $t_{(8)}=3.46, P<0.001$ and $t_{(8)}=0.56, P>0.05 \mathrm{WD} 1 v s \mathrm{WD} 30$ (active and inactive respectively) for absolute values and paired Student's $t$-test; $t_{(9)}=3.405, P=0.0078$, for relative active presses WD1 $v s$ WD30) despite the insertion of GluA2-lacking AMPARs in D1R-MSN. Indeed, the presence of GluA2-lacking AMPARs was detected at WD30 in a different cohort of mice (mixed two-way ANOVA for normalized EPSCs amplitude at $+40 \mathrm{mV}$ : cell-type effect, $F_{(1,29)}=3.156, P=0.0861$; treatment effect, $F_{(1,29)}=9.872, P=0.0038$; cell-type $\times$ treatment, $\quad F_{(1,29)}=8.944, \quad P=0.0056$; Bonferroni post-test: $t_{(16)}=4.455, P<0.001$ for coc. $v s$ sal.; $t_{(19)}=3.27, P<0.001$ for D1 vs D2-MSN and for RI: cell-type effect, $F_{(1,29)}=8.985$, $P=0.0055$; treatment effect, $F_{(1,29)}=16.1, \quad P=0.0004$; cell-type $\times$ treatment, $F_{(1,29)}=11.98, P=0.0017$; Bonferroni post-test for RI: $t_{(16)}=5.429, P<0.001$ for coc. $v s$ sal.; $t_{(19)}=5.32, P<0.001$ for D1 vs D2-MSN) (Figure 4e-g).

We then asked whether this strong response on WD1 might blunt the incubation of the seeking response because of the regular dose of cocaine and a high rate of infusion during acquisition. To test this hypothesis, another cohort of mice acquired SA using double dose per infusion $(1.5 \mathrm{mg} / \mathrm{kg})$ throughout the 10 days. This caused very low rates of responding but still produced an escalation of the intake (ANOVA for repeated measures: session effect, $\left.F_{(9,289)}=11.91, \quad P<0.0001\right)$ and a good discrimination between the two levers (mixed two-way ANOVA for matched data: lever effect, $F_{(1,504)}=103.4, P<0.0001$; session effect, $F_{(9,504)}=1.78, P=0.07$; lever $\times$ session, $F_{(9,504)}=0.70$, $P=0.705$ ) (Figure $4 \mathrm{c}$ ). During the cue-induced cocaineseeking sessions, a very low number of active lever presses was observed at WD1 $(65 \pm 10.7)$ that was significantly higher by WD30 ( $85 \pm 10.4$, Figure $4 \mathrm{~d})$, showing incubation of cocaine craving (mixed two-way ANOVA for repeated measures: lever effect, $F_{(1,20)}=20.71, P=0.0002$; session effect, $F_{(1,20)}=0.58, P=0.46$; lever $\times$ session, $F_{(1,20)}=7.32$, $P=0.0136$; Bonferroni post-test: $t_{(10)}=2.93, P<0.05$ and $t_{(10)}=5.27, P<0.001$ for active $v s$ inactive (WD1 and WD30, respectively); $t_{(9)}=2.45, P<0.05$ and $t_{(9)}=1.38, P>0.05$ WD1 vs WD30 (active and inactive respectively) for absolute values and Student's $t$-test: $t_{(10)}=2.791 ; P=0.0191$ for relative values of active presses WD1 vs WD30). For the first time, rectifying $I-V$ relationships were observed in both D1-MSN and D2-MSN (mixed two-way ANOVA for normalized EPSCs amplitude at $+40 \mathrm{mV}$ : cell-type effect, $F_{(1,37)}=1.26, \quad P=0.2689 ;$ treatment effect, $F_{(1,37)}=12.8$, $P=0.001$; cell type $\times$ treatment, $F_{(1,37)}=0.022, P=0.882$; Bonferroni post-test: $t_{(22)}=2.706, P<0.05$ and $t_{(16)}=2.364$, $P<0.05$ for coc. $v s$ sal. in D1 and D2-MSN, respectively, and for RI: cell-type effect, $F_{(1,37)}=0.6573, P=0.42$; treatment effect, $\quad F_{(1,37)}=20.67, \quad P<0.0001 ; \quad$ cell-type $\times$ treatment, $F_{(1,37)}=0.1252, P=0.72$; Bonferroni post-test: $t_{(22)}=3.044$, $P<0.001$ and $t_{(16)}=3.379, P<0.001$ for coc. $v s$ sal. in $\mathrm{D} 1$ and D2-MSN) (Figure 4e-g).

In summary, incubation of cocaine craving was evidenced with this third condition of SA that was characterized by a very low response rate on the active lever during acquisition, a weak seeking response on WD1, and the presence of GluA2-lacking AMPARs in both MSN subtypes.

\section{GluA2-Lacking AMPARs at BLA to D2-MSN Synapses with Incubation of Cocaine Craving}

We next tested input selectivity for the presence of GluA2lacking AMPARs evoked by the long access and high dose of cocaine onto both D1 and D2-MSN. We prepared NAc slices of Drd1a-td-tomato mice previously infected with AVV-ChR2-EYFP in BLA or mPFC at WD30 (Figure 5a) to record AMPAR-EPSCs in D1 and D2-MSN. At the mPFC input to the NAc, we found the presence of GluA2-lacking AMPARs when recordings were performed from D1-MSN but not D2-MSN (mixed two-way ANOVA for normalized EPSCs amplitude at $+40 \mathrm{mV}$ : cell-type effect, $F_{(1,26)}=16.08$, $P=0.0005$; treatment effect, $F_{(1,26)}=15.26, P=0.0006$; cell type $\times$ treatment, $F_{(1,26)}=20.83, P=0.0001$; Bonferroni posttest: $t_{(16)}=5.66, P<0.001$ for coc. $v s$ sal. in D1-MSN; $t_{(16)}=5.88, P<0.001$ for D1 vs D2-MSN after cocaine and for RI: cell-type effect, $F_{(1,26)}=15.34, P=0.0006$; treatment effect, $\quad F_{(1,26)}=13.15, \quad P=0.0012$; cell type $\times$ treatment, $F_{(1,26)}=14.32, P=0.0008$; Bonferroni post-test: $t_{(16)}=6.47$, $P<0.001$ for coc. $v s$ sal. in D1-MSN; $t_{(16)}=6.548, P<0.001$ for D1 vs D2-MSN after cocaine; Figure $5 \mathrm{~b}$ ) whereas at BLA input the converse was observed: rectifying AMPA $I-V$ relationship in D2-MSN but not D1-MSN (mixed twoway ANOVA for normalized EPSCs amplitude at $+40 \mathrm{mV}$ : cell-type effect, $\quad F_{(1,35)}=5.617, \quad P=0.0235 ; \quad$ treatment effect, $\quad F_{(1,35)}=3.709, \quad P=0.0623$; cell type $\times$ treatment, $F_{(1,35)}=4.161, P=0.049$; Bonferroni post-test: $t_{(19)}=3.498$, $P<0.01$ for coc. $v s$ sal. in D2-MSN; $t_{(19)}=3.395, P<0.01$ for D2 vs D1-MSN after cocaine) and for RI (mixed two-way ANOVA for RI: cell-type effect, $F_{(1,35)}=8.287, P=0.0068$; treatment effect, $F_{(1,35)}=7.028, P=0.012$; cell type $\times$ treatment, $\quad F_{(1,35)}=11.51, \quad P=0.0017 ; \quad$ Bonferroni post-test: $t_{(19)}=5.331, \quad P<0.001$ for coc. $v s$ sal. in D2-MSN; $t_{(19)}=4.829, P<0.001$ for D2 vs D1-MSN after cocaine; 
a

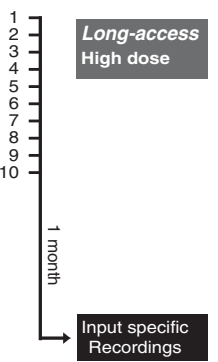

b

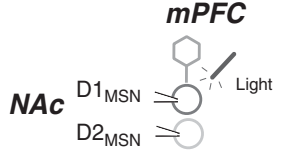

C

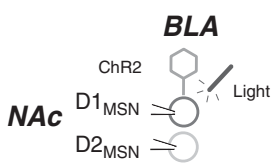

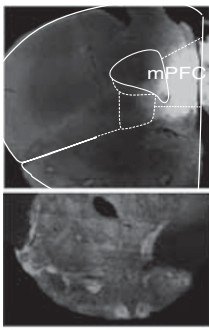
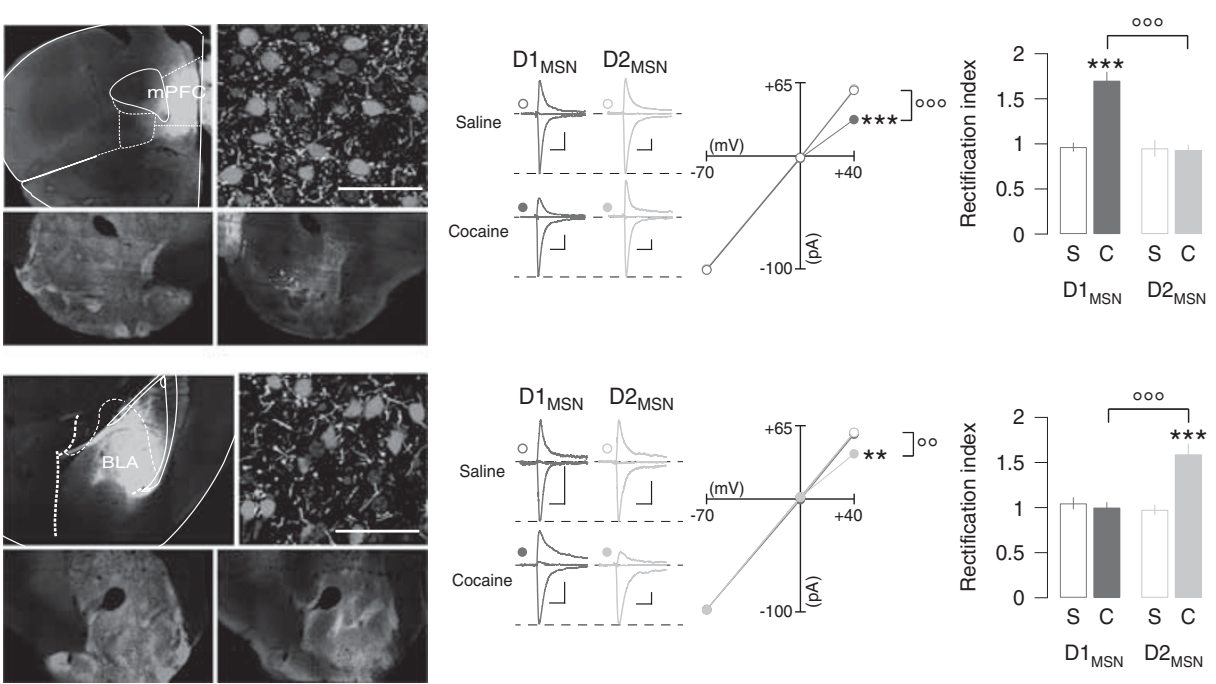

Figure 5 Input-specific insertion of GluA2-lacking AMPARs in DIR- and D2R-MSN. (a) Recordings were performed 30 days after the end of SA acquisition of cocaine ( $1.5 \mathrm{mg} / \mathrm{kg} /$ infusion in $6 \mathrm{~h}$ daily sessions). (b) Schematic of whole-cell recordings of DI- or D2-MSN from mice infected with ChR2 in the medial prefrontal cortex (mPFC). EPSCs were evoked with optogenetic. Confocal pictures of the infected region and of the nucleus accumbens showing ChR2-eYFP from an example DrD I atd-tomato mouse. High magnification image of eyfp-ChR2 terminals surrounding tomato positive and negative neurons, together with nuclear staining (blue), scale bar $50 \mu \mathrm{m}$. Example traces of AMPAR-EPSCs recorded at $-70,0$ and $+40 \mathrm{mV}$, I/V relationship and quantification of the rectification index ( $N=6-12$ cells, from 4 sal. and 4 coc. treated mice). (c) The same experiment that is described in (b) except that the data were obtained from mice with ChR2 in basolateral amygdala (BLA) $(N=5-13$, from 4 sal. and $4 \mathrm{coc}$. treated mice). Bonferroni post-test $* * P<0.01$ or $* * * P<0.001$, for cocaine vs saline and ${ }^{\circ} \mathrm{P}<0.01{ }^{\circ 00} \mathrm{P}<0.00$ I for DI vs D2. Data are expressed as mean \pm SEM. AMPAR, $\alpha$-amino-3-hydroxy-5-methyl-4-isoxazolepropionic acid receptor; EPSC, excitatory postsynaptic current; MSN, medium-sized spiny neuron. A full color version of this figure is available at the Neuropsychopharmacology journal online.

Figure 5c). These data were obtained from male and female mice; however, insertion of GluA2-lacking AMPAR was observed in both (Supplementary Figure 2). These results demonstrate that both cell-type and input-specific characterization is required to identify the behaviorally relevant circuit dysfunction.

\section{DISCUSSION}

Our observations demonstrate the presence of GluA2-lacking AMPARs in D1R-expressing MSN synapses after withdrawal from contingent and non-contingent cocaine exposure. We also show that the exposure to a high dose of cocaine is required to induce incubation of cocaine craving along with the expression of GluA2-lacking AMPARs selectively at BLA to D2R-MSN synapses.

Direct comparison of non-contingent and contingent cocaine exposure show that both lead to the appearance of GluA2-lacking AMPARs in the NAc, provided that the exposure is followed by a withdrawal period. We even found that a single, passive injection of cocaine is sufficient to drive insertion of GluA2-lacking AMPARs. This insertion was only observed in D1-MSN, which could explain why this condition is sufficient to increase mEPSCs in D1-MSN and to induce locomotor sensitization (Pascoli et al, 2011; Valjent et al, 2010), and why sampling from unidentified MSN may lead to failure to observe rectifying AMPAR-EPSCs (Mameli et al, 2009). Moreover, this result is in line with the fact that mGluR-dependent LTD is able to reverse both synaptic plasticity and locomotor sensitization evoked with this condition (Creed et al, 2015). Indeed mGluRs stimulation seems to represent an efficient mechanism to remove synaptic GluA2-lacking AMPARs from several brain circuits (Bellone et al, 2008; Loweth et al, 2014). We also observed insertion of GluA2-lacking AMPARs after cocaine SA regardless of the duration of access $(2$ or $6 \mathrm{~h}$ ), as recently demonstrated (Ma et al, 2014; Pascoli et al, 2014).

In all conditions D1-MSN expressed GluA2-lacking AMPARs. We also saw an increase in $\mathrm{A} / \mathrm{N}$ ratio and strong locomotor sensitization or seeking response. To fully understand the relationship between increased $\mathrm{A} / \mathrm{N}$ ratio and rectification, further studies will be needed to determine whether cocaine exposure also affects NMDAR-mediated synaptic transmission in the NAc. This seems plausible, because days after non-contingent cocaine exposure an increase in GluN2-containing NMDAR was detected that correlated with an increase in silent synapses ( Huang et al, 2009; Brown et al, 2011; Lee and Dong, 2011; Lee et al, 2013). Subsequent insertion of GluA2-lacking AMPARs thus occurs during withdrawal from cocaine exposure at NMDA-only, silent synapses that do not contribute to excitatory transmission. Studies taking advantage of input-specific approaches show that high $\mathrm{A} / \mathrm{N}$ ratio is specifically expressed at inputs from the ventral subiculum of the hippocampus and responsible for the vigor of cocaine seeking (Pascoli et al, 2014) as well as for a strong sensitized locomotor response (Britt et al, 2012). By increasing excitatory transmission onto D1R-expressing MSN, an imbalance between direct and indirect pathway output from the NAc may be created. In addition, the insertion of GluA2-lacking AMPAR not only strengthens the inputs but also makes them calcium permeable, which may alter the induction rules for activitydependent plasticity. Together these changes may enhance motivation to seek the drug in the presence of the drugassociated context. 
The striking result here is the demonstration that the presence of GluA2-lacking AMPARs in D1-MSN is not necessarily associated with an incubation of cocaine craving. We did not observe incubation of cocaine craving with a $0.75 \mathrm{mg} / \mathrm{kg}$ dose, even in a long access protocol. This result may sound surprising especially regarding precedent study showing that $0.5 \mathrm{mg} / \mathrm{kg} / \mathrm{inf}$. was sufficient to induce such an effect (Halbout et al, 2014). The difference may reside in an overnight, ad libitum access to cocaine to kick-start SA or the food shaping used in these studies. When comparing the three conditions of cocaine SA used in the present study, some elements could help to understand why incubation of cocaine craving was seen only with the highest cocaine dose. First, the lever discrimination was similar in all three conditions; however, the rate of active lever presses during acquisition was much higher in the regular dose conditions $(0.75 \mathrm{mg} / \mathrm{kg} /$ infusion$)$ than with the high dose. The rate of active lever presses reached at the end of the acquisition period was correlated with the number of lever presses performed on WD1 and seemed to occlude the detection of an incubation of cocaine craving. Second, the specific form of synaptic plasticity (BLA onto D2R-MSN) only observed with the high cocaine dose might result from higher peak concentration with each infusion.

The insertion of the GluA2-lacking AMPARs in D2-MSN was observed only when mice were exposed to a high dose of cocaine and was uniquely associated with an incubation of cocaine craving. The presence of excitatory synaptic plasticity in D2-MSN may be related to negative effects that only occur at higher concentrations (Carelli and West, 2014; Danjo et al, 2014). As a result aversion learning may be triggered, of which the plasticity in the D2R-MSN may constitute a cellular correlate. In this scenario, cocaineevoked plasticity on D2R-MSN would be DA independent, because the stimulation of the $\mathrm{D} 2$ receptor and subsequently the activation of the inhibitory $G$ protein $\left(G_{i o}\right)$ are not known to trigger potentiation of excitatory transmission. Consequently, this process could curb the active lever responses of mice in this condition. In line with this argument, D2 receptors play an important role in limiting the rate of cocaine high-dose SA (Caine et al, 2002). Moreover, synaptic plasticity onto D2-MSN was associated with resilience to compulsive cocaine use (Bock et al, 2013). For the specificity of the input, that is, the basolateral amygdala, a causal link has been found between incubation of cocaine craving and GluA2-lacking AMPARs in rats (Lee et al, 2013).

Insertion of GluA2-lacking AMPARs appears to be a general response of neurons to cocaine exposure in brain regions of the reward circuit (Lüscher and Malenka, 2011). This may represent a form of metaplasticity that changes the rules for subsequent activity- and experience-dependent plasticity. As a proof of principle excitatory afferents onto VTA DA neurons can undergo a Hebbian LTP when depolarized during afferent activity (Mameli et al, 2011). After cocaine exposure, an anti-Hebbian LTP emerges, where potentiation is induced, when the neurons are hyperpolarized during afferent activity. The removal of GluA2-lacking AMPARs that require mGluRs stimulation, restores baseline rules of plasticity. In this case induction of LTP becomes again Hebbian and NMDAR dependent.
Our observations suggest that common neuroadaptations could enable incentive motivation to drug-associated cue effects whichever the mode of cocaine administrations (Robinson and Berridge, 1993). Although behavioral studies have not firmly established a role for sensitization in the relapse in humans, experiments have demonstrated a remarkable overlap in the neurocircuitry and both require learning (Steketee and Kalivas, 2011). For instance, learning of drug-associated cues in locomotor sensitization is shown by the fact that a novel environment paired with cocaine administration facilitates sensitization (Badiani and Robinson, 2004). Introduction of a novel environment for the cocaine challenge, different from the home cage and different from the cocaine-associated environment, precludes locomotor sensitization (Valjent et al, 2010). It is therefore not surprising that some neuroadaptations observed in the NAc could be shared by locomotor sensitization and cueinduced cocaine seeking. Future studies will have to address how these apparent similar types of plasticity can explain different types of addictive behaviors induced by active and passive cocaine administration.

Taken together, the present study demonstrates the power of characterizing drug-evoked synaptic plasticity in identified MSN along with optogenetic projection targeting to elucidate how addictive drugs change accumbal integration. With this insight it will be possible to extend and refine the circuit model of addiction and eventually predict the most efficient treatment strategies.

\section{FUNDING AND DISCLOSURE}

The authors declare no conflict of interest. The study was supported by an advanced grant of the European Research Council (ERC) to CL. VP and JT were supported by the Swiss National Science Foundation (Ambizione fellowship and MD-PHD grant). Further funding to CL comes from the Academic Society of Geneva and Carigest SA and the 'Fondation privée des Hôpitaux Universitaires de Genève'.

\section{ACKNOWLEDGMENTS}

We thank the members of the Lüscher lab for many discussions.

\section{REFERENCES}

Ahmed SH, Koob GF (1998). Transition from moderate to excessive drug intake: change in hedonic set point. Science 282: 298-300.

Badiani A, Robinson TE (2004). Drug-induced neurobehavioral plasticity: the role of environmental context. Behav Pharmacol 15: 327-339.

Bellone C, Lüscher C, Mameli M (2008). Mechanisms of synaptic depression triggered by metabotropic glutamate receptors. Cell Mol Life Sci 65: 2913-2923.

Bock R, Shin JH, Kaplan AR, Dobi A, Markey E, Kramer PF et al (2013). Strengthening the accumbal indirect pathway promotes resilience to compulsive cocaine use. Nat Neurosci 16: 632-638.

Boudreau AC (2005). Behavioral sensitization to cocaine is associated with increased AMPA receptor surface expression in the nucleus accumbens. J Neurosci 25: 9144-9151.

Boudreau AC, Reimers JM, Milovanovic M, Wolf ME (2007). Cell surface AMPA receptors in the rat nucleus accumbens increase 
during cocaine withdrawal but internalize after cocaine challenge in association with altered activation of mitogen-activated protein kinases. J Neurosci 27: 10621-10635.

Britt JP, Benaliouad F, McDevitt RA, Stuber GD, Wise RA, Bonci A (2012). Synaptic and behavioral profile of multiple glutamatergic inputs to the nucleus accumbens. Neuron 76: 790-803.

Brown TE, Lee BR, Mu P, Ferguson D, Dietz D, Ohnishi YN et al (2011). A silent synapse-based mechanism for cocaine-induced locomotor sensitization. J Neurosci 31: 8163-8174.

Caine SB, Negus SS, Mello NK, Patel S, Bristow L, Kulagowski J et al (2002). Role of dopamine D2-like receptors in cocaine selfadministration: studies with D2 receptor mutant mice and novel D2 receptor antagonists. J Neurosci 22: 2977-2988.

Carelli RM, West EA (2014). Neuropharmacology. Neuropharmacology 76: 360-369.

Conrad KL, Tseng KY, Uejima JL, Reimers JM, Heng L-J, Shaham Y et al (2008). Formation of accumbens GluR2-lacking AMPA receptors mediates incubation of cocaine craving. Nature 454: $118-121$

Creed M, Pascoli VJ, Lüscher C (2015). Addiction therapy. Refining deep brain stimulation to emulate optogenetic treatment of synaptic pathology. Science 347: 659-664.

Danjo T, Yoshimi K, Funabiki K, Yawata S, Nakanishi S (2014). Aversive behavior induced by optogenetic inactivation of ventral tegmental area dopamine neurons is mediated by dopamine D2 receptors in the nucleus accumbens. Proc Natl Acad Sci USA 111: 6455-6460.

Gawin FH, Morgan C, Kosten TR, Kleber HD (1989). Double-blind evaluation of the effect of acute amantadine on cocaine craving. Psychopharmacol 97: 402-403.

Grimm JW, Hope BT, Wise RA, Shaham Y (2001). Nature 412: $141-142$

Halbout B, Bernardi RE, Hansson AC, Spanagel R (2014). Incubation of cocaine seeking following brief cocaine experience in mice is enhanced by mGluR1 blockade. J Neurosci 34: 1781-1790.

Huang YH, Lin Y, Mu P, Lee BR, Brown TE, Wayman G et al (2009). In vivo cocaine experience generates silent synapses. Neuron 63: 40-47.

Jonas P, Burnashev N (1995). Molecular mechanisms controlling calcium entry through AMPA-type glutamate receptor channels. Neuron 15: 987-990.

Kourrich S, Rothwell PE, Klug JR, Thomas MJ (2007). Cocaine experience controls bidirectional synaptic plasticity in the nucleus accumbens. J Neurosci 27: 7921-7928.

Lee BR, Dong Y (2011). Cocaine-induced metaplasticity in the nucleus accumbens: silent synapse and beyond. Neuropharmacology 61: 1060-1069.

Lee BR, Ma Y-Y, Huang YH, Wang X, Otaka M, Ishikawa M et al (2013). Maturation of silent synapses in amygdala-accumbens projection contributes to incubation of cocaine craving. Nat Neurosci 2013 16: 1644-1651.

Liu SJ, Zukin RS (2007). Ca2+-permeable AMPA receptors in synaptic plasticity and neuronal death. Trends Neurosci 30: 126-134.

Loweth JA, Scheyer AF, Milovanovic M, LaCrosse AL, Flores-Barrera E, Werner CT et al (2014). Synaptic depression via mGluR1 positive allosteric modulation suppresses cueinduced cocaine craving. Nat Neurosci 17: 73-80.

Lüscher C (2013). Drug-evoked synaptic plasticity causing addictive Behavior. J Neurosci 33: 17641-17646.

Lüscher C, Malenka RC (2011). Drug-evoked synaptic plasticity in addiction: from molecular changes to circuit remodeling. Neuron 69: 650-663.
Ma Y-Y, Lee BR, Wang X, Guo C, Liu L, Cui R et al (2014). Bidirectional modulation of incubation of cocaine craving by silent synapse-based remodeling of prefrontal cortex to accumbens projections. Neuron 83: 1453-1467.

Mameli M, Bellone C, Brown MTC, Lüscher C (2011). Cocaine inverts rules for synaptic plasticity of glutamate transmission in the ventral tegmental area. Nat Neurosci 14: 414-416.

Mameli M, Halbout B, Creton C, Engblom D, Parkitna JR, Spanagel R et al (2009). Cocaine-evoked synaptic plasticity: persistence in the VTA triggers adaptations in the NAc. Nat Neurosci 12: 1036-1041.

Mccutcheon JE, Wang X, Tseng KY, Wolf ME, Marinelli M (2011). Calcium-permeable AMPA receptors are present in nucleus accumbens synapses after prolonged withdrawal from cocaine self-administration but not experimenter-administered cocaine. J Neurosci 31: 5737-5743.

Nelson AB, Hang GB, Grueter BA, Pascoli V, Lüscher C, Malenka RC et al (2012). A comparison of striatal-dependent behaviors in wild-type and hemizygous Drd1a and Drd2 BAC transgenic mice. J Neurosci 32: 9119-9123.

Nestler EJ (2013). Cellular basis of memory for addiction. Dialogues Clin Neurosci 15: 431-443.

Ortinski PI, Vassoler FM, Carlson GC, Pierce RC (2012). Temporally dependent changes in cocaine-induced synaptic plasticity in the nucleus accumbens shell are reversed by D1-like dopamine receptor stimulation. Neuropsychopharmacology 37: 1671-1682.

Pascoli V, Terrier J, Espallergues J, Valjent E, O'Connor EC, Lüscher C (2014). Contrasting forms of cocaine-evoked plasticity control components of relapse. Nature 509: 459-464.

Pascoli V, Turiault M, Lüscher C (2011). Reversal of cocaine-evoked synaptic potentiation resets drug-induced adaptive behaviour. Nature 481: 71-75.

Pickens CL, Airavaara M, Theberge F, Fanous S, Hope BT, Shaham Y (2011). Neurobiology of the incubation of drug craving. Trends Neurosci 34: 411-420.

Pierce RC, Bell K, Duffy P, Kalivas PW (1996). Repeated cocaine augments excitatory amino acid transmission in the nucleus accumbens only in rats having developed behavioral sensitization. J Neurosci 16: 1550-1560.

Robinson TE, Berridge KC (1993). The neural basis of drug craving: an incentive-sensitization theory of addiction. Brain Res Rev 18: 247-291.

Steketee JD, Kalivas PW (2011). Drug wanting: behavioral sensitization and relapse to drug-seeking behavior. Pharmacol Rev 63: 348-365.

Valjent E, Bertran-Gonzalez J, Aubier B, Greengard P, Hervé D, Girault J-A (2010). Mechanisms of locomotor sensitization to drugs of abuse in a two-injection protocol. Neuropsychopharmacology 35: 401-415.

Valjent E, Corvol J-C, Trzaskos J, Girault J-A, Hervé D (2006). Valjent_2006_BMC Neuroscience ERK locomotion. BMC Neurosci 7: 20.

Verdoorn TA, Burnashev N, Monyer H, Seeburg PH, Sakmann B (1991). Structural determinants of ion flow through recombinant glutamate receptor channels. Science 252: 1715-1718.

Wolf ME, Ferrario CR (2010). AMPA receptor plasticity in the nucleus accumbens after repeated exposure to cocaine. Neurosci Biobehav Rev 35: 185-211.

Xi Z-X, Li X, Li J, Peng X-Q, Song R, Gaál J et al (2012). Blockade of dopamine D3 receptors in the nucleus accumbens and central amygdala inhibits incubation of cocaine craving in rats. Addict Biol 18: 665-677.

Supplementary Information accompanies the paper on the Neuropsychopharmacology website (http://www.nature.com/npp) 